\title{
BOXTARIK (BOX PINTAR LISTRIK) INOVASI MEDIA PEMBELAJARAN DENGAN MEMANFAATKAN LIMBAH BOTOL OLI
}

\author{
Toyib Wahyu Nugroho ${ }^{1}$, Nusroh Wulandari ${ }^{2}$, Henry Setya Budhi ${ }^{3}$ \\ ${ }^{1}$ Institut Agama Islam Negeri Kudus \\ Jalan Conge Ngembalrejo No.51, Ngembalrejo Bae, Kabupaten Kudus, Jawa Tengah 59322 \\ Email : toyibwahyunugroho@gmail.com
}

\begin{abstract}
One of the most important components in the learning process is learning media. Hamlik (1986) suggests that the use of instructional media in the teaching and learning process can increase new desires and interests, increase motivation and stimulation of learning activities, and even bring psychological effects to students. Utilization of used goods and simple equipment as a medium of learning is not something new in the world of education. As is known, waste is a major problem in Indonesia. Based on data from the Central Bureau of Statistics in 2014 shows that Indonesia produces around 187.2 million tons / year of waste and ranks second as the largest waste producer in the world. Waste does not only come from households but also from the automotive environment, for example used oil bottles. Making learning media from used oil bottles aims to arouse creativity and also instill environmental care, so that they will strive to maintain life for the next, besides that it can also grow the entrepreneurial spirit if it can develop its creativity in making learning media. This study uses an experimental method to obtain appropriate learning media and literature studies from several books, journal articles, and other relevant sources.
\end{abstract}

Abstrak:Salah satu komponen terpenting dalam proses belajar yaitu media pembelajaran. Hamlik (1986) mengemukakan bahwa penggunaan media pembelajaran dalam proses belajar mengajar dapat meningkatkan keinginan dan minat yang baru, meningkatkan motivasi dan rangsangan kegiatan belajar, dan bahkan membawa pengaruh-pengaruh psikologis terhadap siswa. Pemanfaatan barang bekas sebagai dan peralatan sederhana sebagai media pembelajaran bukanlah sesuatu yang baru pada dunia pendidikan. Seperti diketahui sampah merupakan masalah pokok di indonesia. Berdasarkan data dari Badan Pusat Statistik 2014 menunjukkan bahwa Indonesia menghasilkan sampah sekitar 187,2 juta ton/ tahun dan menempati urutan kedua sebagai penghasil sampah terbesar di dunia. Sampah tak hanya berasal dari rumah tangga namun juga dari lingkungan otomotif, contohnya botol bekas oli. Pembuatan Media pembelajaran dari botol oli bekas bertujuan untuk membangkitkan kreativitas dan juga menanamkan sifat peduli lingkungan, sehingga mereka akan berusaha untuk menjaga kehidupan untuk selanjutnya, selain itu juga dapat menumbuhkan juwa kewirausahaan juka dapat mengembangkan kreatifitasnya dalam pembuatan media pembelajaran. penelitian ini menggunakan metode eksperimen untuk mendapatkan media pebelajaran yang sesuai dan juga studi pustaka dari beberapa buku, artikel jurnal, maupun sumber lainnya yang relevan.

(C) 2019 Physics Education Department, STKIP PGRI Lubuklinggau, Indonesia

Kata kunci: Media pembelajaran, Boxtarik, Pemanfaatan limbah.

\section{PENDAHULUAN}

Perkembangan teknologi yang

beberapa tahun belakangan ini mengalami

kemajuan yang sangat pesat menjadikan

para tenaga pendidik harus pintar dalam

mengimbanginya dan menyelaraskannya

dengan dunia pendidikan. Para pendidik harus pintar dalam menyajikan pembelajaran yang interaktif sehingga para murid tertaik dalam pembelajaran yang disampaikan oleh sang guru. Guru yang dianggap sebagai seorang penyampai materi (fasilitator) pembeajaran tidak hanya menyampaiakn 
pembelajarn bahan ajar sesuai dengan rancangan program pembelajaran yang sudah ditentukan namun juga guru dituntut memberikan kemudahan pada siswa dalam menyajikan pembelajaran sehingga para siswa mudah menyerap ilmu pengetahuan yang disampaikan guru. Guru yang profesional memiliki empat kompetensi seperti digariskan pada UU No. 19 Tahun 2013 tentang guru, yaitu: kompetensi pedagogik, kepribadian, social, dan prosfesional. Kompetensi pedagogik menuntun guru agar dapat melaksanakan dengan baik jika guru dapat merencanakan atau merancang pembelajarn dengan sistematis dan cermat. Salah satu komponen yang perlu mendapat perhatian dalam perencanaan pendidikan pembelajaran adalah pemilihan media pembelajaran yang sesuai. (Nuzulia, 2016)

Hamlik (1986) mengemukakan bahwa penggunaan media pembelajaran dalam proses belajar mengajar dapat meningkatkan keinginan dan minat yang baru, meningkatkan motivasi dan rangsangan kegiatan belajar, dan bahkan membawa pengaruh-pengaruh psikologis terhadap siswa. Penggunaan media pembelajaran pada tahap orientasi pembelajaran akan sangat membantu efektifitas proses pembelajaran dan penyampaian pesan pembelajaran pada saat itu. Disamping itu juga media pembelajaran juga dapat membantu siswa meningkatkan pemahaman, menyajikan data dengan menarik, memudahkan penafsiran data dan memadatkan informasi karena data dibuat dengan sesederhana dan seringkas mungkin tanpa melupakan unsur-unsur yang penting, serta meningkatkan motivasi dan minat siswa dalam belajar karna pembelajaran yang sangat interaktif dan menarik untuk diikuti. (sutjipto, 2011)

Semakin sadarnya orang terhadap pentingnya media pembelajarn yang sangat membantu dalam proses belajar menjadikan kita sadar bahwa pengelolalan dan penembangan media pembelajarn sangat dibutuhkan. Pemilihan media pembelajarn ini perlu mendapat perhatian karena fungsi media sangat stategis dalam pelaksanaan pembelajaran. Pembelajaran akan menarik dan mudah dipahami oleh pembelajar bila guru merancang media secara cermat dan dapat menggunakan sesuai fungsinya. (Anitah, 2010). Karena memang belajar merupakan proses integral yang dialami setiap manusia maka manusia akan selalu mencari pembaruan yang pas sesuai dengan masanya. Dalam pembuatan media pembelajaran harus memperhatikan dua hal yaitu unik dan spesifik. Unik maksudnya dalam pembuatan media 
pembelajarn haru mampu menarik minat para siswa oleh karena itu media pembelajarannya harus disesuaikan dengan karateristik siswanya. Yang kedua yaitu spesifik, yaitu dalam membuat media pembelajaran haruslah memperhatikan tujuan pembelajaran sehingga pesan yang ingin disampaikan dalam pembelajarn dapat mudah dapat dipahami oleh siswa. Dengan memperhatiakn dua hal ini maka media pembelajarn yang dibuat akan semakin tepat guna.

Pemanfaatan barang bekas sebagai dan peralatan sederhana sebagai media pembelajarn bukanlah sesuatu yang baru pada dunia pendidikan. Sebelum masa modern datang para guru sudah menggunakan barang-barang sederhana dan seadanya sebagai media pembelajaran. Zaman yang belum tersentuh teknologi menyebabkan para guru harus memiliki kreatifitas yang tinggi dan dituntut untuk berkerja keras agar siswanya mampu menyerap pelajaran semaksimal mungkin. Namun di masa sekarang dengan datangnya teknologi yang sangat memudahkan dalam pembelajarn para guru justru terlena dengan dengan kemajuan teknologi yang terjadi. Dunia yang serba canggih memudahkan mereka untuk memecahkan masalah yang ada dalam pembelajaran sehingga jika suatu saat saat teknologi hilang dari jangkauan mereka, maka mreka akan kebingungan dalam melakukan pembelajaran karna media yang biasanya mereka gunakan sudah tidak ada lagi. Akibatnya para guru zaman sekarang kurang peka terhadap potensi ligkungan sekitat yang dapat dijadikan media pembelajaran.

\section{LANDASAN TEORI}

\section{Inovasi Media Pembelajaran}

Media berasal dari kata latin yang merupakan bentuk jamak dari kata "medium" yang memiliki arti perentara atau penghubung. (Riyana, 2008). Media pembelajaran meruapakan sebuah alat yang biasanya di buat sendiri oleh guru untuk menyampikan materi. Hal ini sesuai dengan fungsinya yaitu sebagai perantara materi yang akan disampaikan dengan siswa.Penggunaan media pembelajaran merupakan salah satu cara untuk meningkatkan minat belajar siswa. Media pembelajaran selalu terdiri dari dua unsur penting yaitu alat (hardware) dan pesan (software). Jadi perlu dingat bahwa selain alat yang digunakan menarik minat siswa namun harus memperhatikan pesan atau materi yang ingin disampaikan harus tersampikan sehingga tujuan pembelajaran dapat tercapai. 
Selain dua unsur penting tersebut, penggunaan media pembejaran juga harus memperhatikan banyak diantaranya aspek ketepatan, materi, biaya dan aspek keselamatan.

a. Aspek ketepatan maksudnya media pembelajaran yang digunakan harus menunjang tujuan pembejaran yang telah ditetapkan.

b. Aspek meteri, penggunaan media pembelajaran harus sesuai dengan materi yang disampikan karena penggunaan media yang sesuai materi akan mempengaruhi hasil belajar siswa

c. Aspek biaya yaitu biaya yang dikeluarkan untuk pembelian atau pembuatan media pembelajarn harus sesuai dengan manfaat yang didapatkan

d. Aspek keselamatan dimaksudkan dalam penggunaan media pembelajaran maka harus memperhatikan keselamatan pengguna baik itu guru maupun siswa

Oleh karen itu guru hendaknya menggunakan media pembelajaran yang tepat guna dan ekonomis serta tidak melulu menggunakan media yang tradisional namun juga harus selaras dengan perkembangan teknologi yang ada. Oleh karena itu guru harus memiliki ketrampilan dalam memilih media pembelajaran. (Usman, 2002)

Setelah mengetahui aspek apa saja yang diperhatikan dalam pembuatan media pembelajaran, selanjutnya adalah membuat membuat media pembelajaran yang baru atau yang sering disebut dengan inovasi. Inovasi merupkan suatu ide yang diwujudkan dalam berbagai hal oleh manusia tentang sesuatu yang baru bagi sekelompok orang. inovasi diharapkan mengembangkan yang sudah ada menjadi lebih baik lagi. Terdapat beberapa sumber inovasi diantaranya kebutuhan, ketidakselarasan media yang sudah ada dengan zaman, perkembangan industri, perubahan presepsi, munsulnya pengetahuan-pengetahuan baru serta faktor-faktor tak terduga lainnya.(Dilaga, 2012) Hakikat sebuah pembelajaran adalah suatu hal yang dirancang secara sistematis, dikelola secara kreatif yang bertujuan untuk menciptakan suasana belajar yang kondusif, sehingga hendaknya inovasi media pembelajaran yang diciptakan dapat menunjang hakikat dari sebuah pembelajaran.

\section{Pembelajaran IPA Terpadu}

IPA (science) adalah sebuah ilmu yang yang berpangkal pada hipotesa. IPA juga diartikan sebagai suatu kumpulan ilmu pengetahuan yang bersifat sistematis karena bukan hanya sebagai sebuah ilmu 
pengetahuan yang berupa fakta namun juga sebagai sebuah proses penemuan.(Sulistyorini, 2007). Perkembangan IPA selanjutnya memunculkan metode ilmiah (scientific methods) yang terwujud dalam langkah kerja ilmiah (working scientificaly), nilai dan sikap ilmiah (asictific attitudes).IPA diperlukan dalam kehidupan sehari-hari untuk memenuhi kebutuhan manusia melalui pemecahan masalah yang dapat diidentifikasi. Hal ini sesuai dengan pendidikan IPA yang diharapkan menjadi wahana siswa untuk mempelajari diri sendiri dan lingkungan sekitar yang selanjutnya diharapkan dapat di terapkan dalam kehidupan sehari-hari.(Atmojo, 2017)

Berdasarkan uraian Fogarty tentang keterpaduan, Depdiknas (2006) menyatakan empat diantara keterpaduan sesuai untuk dikembangkan dalam pembelajaran IPA di tingkat satuan pendidikan sekolah menengah di Indonesia. Keempat model yang dimaksud adalah model integrated, shared, webbed, dan connected. Empat model keterpaduan dipilih karena konsepkonsep dalam KD IPA memiliki karakteristik yang berbeda-beda, sehingga memerlukan model yang sesuai agar memberikan hasil yang optimal.
Perbandingan deskripsi karakteristik, kelebihan dan keterbatasan keempat model tersebut dapat dilihat pada Tabel 1 di bawah ini. 
Tabel 1. Perbandingan deskripsi karakteristik, kelebihan dan keterbatasan keempat model

\begin{tabular}{|c|c|c|c|}
\hline Model & Karateristik & kelemahan & Kelebihan \\
\hline Integrate & $\begin{array}{l}\text { - } \text { Membelajarkan } \\
\text { konsep pada } \\
\text { beberapa KD } \\
\text { yang beririsan } \\
\text { atau tumpang } \\
\text { tindih jadi } \\
\text { hanya konsep } \\
\text { yang beririsan } \\
\text { yang diajarkan }\end{array}$ & $\begin{array}{ll}\text { - } & \text { Pemahaman } \\
\text { konsep lebih } \\
\text { utuh (holistik) } \\
\text { - Lebih efisien } \\
\text { - Sangat } \\
\text { konstektual }\end{array}$ & $\begin{array}{l}\text { - KD-KD yang } \\
\text { konsepnya } \\
\text { beririsan } \\
\text { tidak selalu } \\
\text { dalam } \\
\text { semester atau } \\
\text { kelas yang } \\
\text { sama } \\
\text { - Menuntut } \\
\text { wawasan dan } \\
\text { penguasaan } \\
\text { materi yang } \\
\text { luas } \\
\text { - Sarana } \\
\text { prasaran, } \\
\text { misalnya } \\
\text { buku belum } \\
\text { mendukung }\end{array}$ \\
\hline & $\begin{array}{l}\text { - Membelajarkan } \\
\text { beberapa KD } \\
\text { yang berkaitan } \\
\text { melalui sebuah } \\
\text { tema }\end{array}$ & $\begin{array}{l}\text { - Pemahaman } \\
\text { terhadap } \\
\text { konsep utuh } \\
\text { - Kontekstual } \\
\text { Dapat dipilih } \\
\text { tema-tema } \\
\text { menarik yang } \\
\text { dekat dengan } \\
\text { kehidupan }\end{array}$ & $\begin{array}{l}\text { - KD-KD yang } \\
\text { konsepnya } \\
\text { beririsan } \\
\text { tidak selalu } \\
\text { dalam } \\
\text { semester atau } \\
\text { kelas yang } \\
\text { sama } \\
\text { - Tidak mudah } \\
\text { menemukan } \\
\text { tema pengait } \\
\text { yang tepat. }\end{array}$ \\
\hline fisika & $\begin{array}{l}\text { - Membelajarkan } \\
\text { semua konsep } \\
\text { dari beberapa } \\
\mathrm{KD}, \quad \text { dimulai } \\
\text { dari konsep } \\
\text { yang beririsan } \\
\text { sebagai unsur } \\
\text { pengikat }\end{array}$ & $\begin{array}{l}\text { - Pemahaman } \\
\text { terhadap } \\
\text { konsep utuh } \\
\text { - Efisien } \\
\text { - Kontekstual }\end{array}$ & $\begin{array}{l}\text { - KD-KD yang } \\
\text { konsepnya } \\
\text { beririsan } \\
\text { tidak selalu } \\
\text { dalam } \\
\text { semester atau } \\
\text { kelas yang } \\
\text { sama } \\
\text { - Menuntut } \\
\text { wawasan dan } \\
\text { penguasaan } \\
\text { materi yang } \\
\text { luas } \\
\text { - Sarana- } \\
\text { prasarana, }\end{array}$ \\
\hline
\end{tabular}




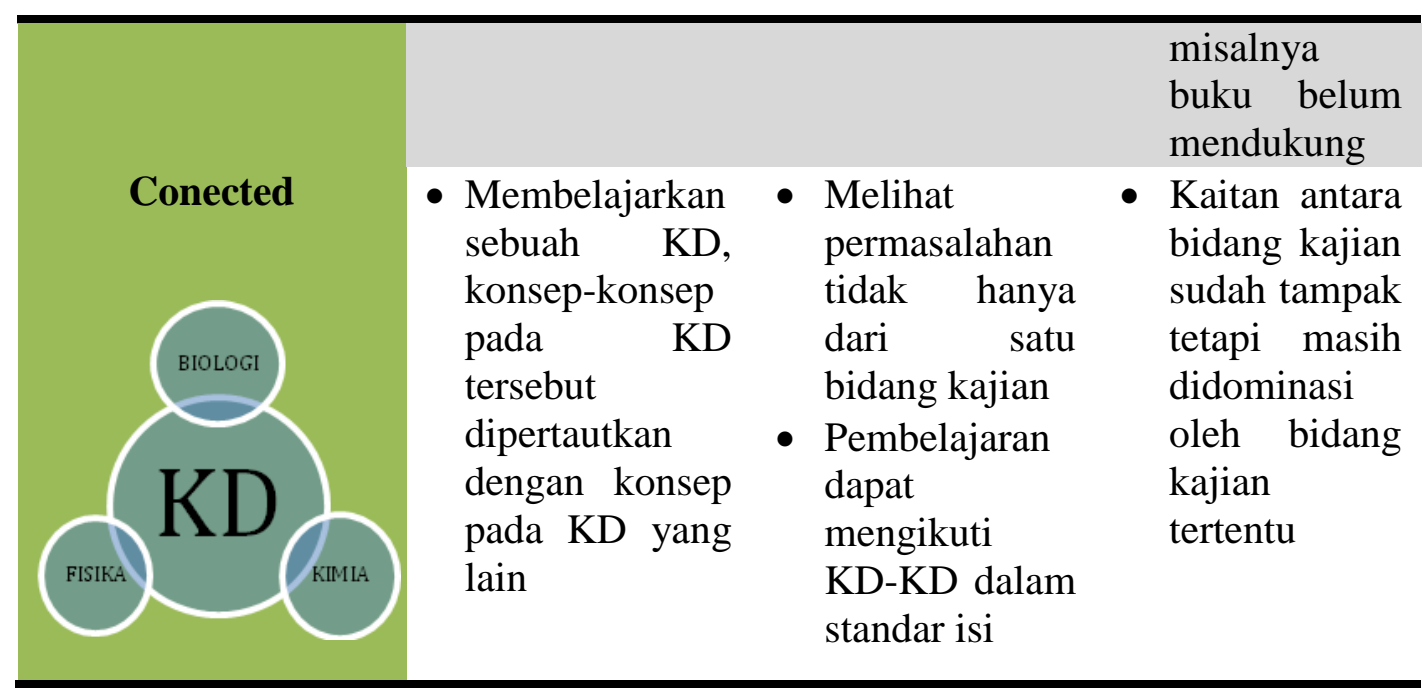

Sumber (Wilujeng, 2011)

Diantara keempat model keterpaduan IPA, model shared merupakan model yang paling sesuai dengan inivasi media pembelajaran yang dilakukan, yaitu dengan membuat rangkaian listrik sebagai konsep yang terdiri dari sub bahasan fisika yaitu rangkaian listrik seri dan pararel serta kimia dengan sub tema reaksi kimia yang terjadi pada baterai.

\section{METODE}

\section{PENELITIAN/EKSPERIMEN}

1. Rancangan penelitian

Rancangan penelitian yang kami lakukan yaitu

a. Mengidentifikasi dan memilih masalah pembelajaran IPA pada sekolah menengah

b. Merumuskan pemanfaatan limbah sebagai media pembelajaran

c. Melakukan kajian pustaka d. Melakukan perancangan dan pembuatan BOXTARIK

e. Mengadakan analisis pustaka

f. Menarik kesimpulan dan generalisasi

2. Teknik pengumpulan data

Teknik pengumpulan data yang digunakan dalam penelitian ini yaitu teknik pengamatan, eksperimen dan studi pustaka. Pengamatan dilakukan untuk mengatahui masalah-masalah yang terjadi dalam pembelajaran IPA di sekolah menengah. Eksperime yang dilakukan penulis bertujuan untuk membuat inovasi media pembelajaran IPA serta studi pustaka untuk mengumpulkan data dari berbagai sumber seperti buku maupun jurnal yang kemudian dianalisis sehingga mendapatkan data yang dibutuhkan.

3. Teknik analisa data 
Data yang diperoleh selanjutnya dianalisa menggunakan teknik naratif dan deskripsi hasil data.

\section{HASIL DAN PEMBAHASAN}

Inovasi BOXTARIK (Box Pintar Listrik) ini tak lain ditujukan untuk menunjang pemahaman siswa dalam memahami konsep kelistrikan dalam ilmu fisika, dan keterpaduannya dengan materi kimia. Sehingga nantinya siswa tidak hanya memahami konsep dasarnya saja, dan bisa mengembangakan penerapan sederhana dari rancangan BOXTARIK tersebut. Hal yang mendasari adanya inovasi BOXTARIK ini salah satunya yaitu karena banyaknya botol oli bekas yang tidak banyak dimanfa'atkan sebagai media pembelajaran. Dalam hal ini, peralatan dan bahan untuk membuat BOXTARIK yaitu:

1. Botol oli bekas (2)

2. Cutter

3. Gunting

4. Dinamo

5. Kabel

6. Kawat email

7. Lampu led

8. Baterai

9. Baterai holder

10. Solder

11. Capit buaya

12. Lem lilin
13. Lem altico

14. Kardus bekas

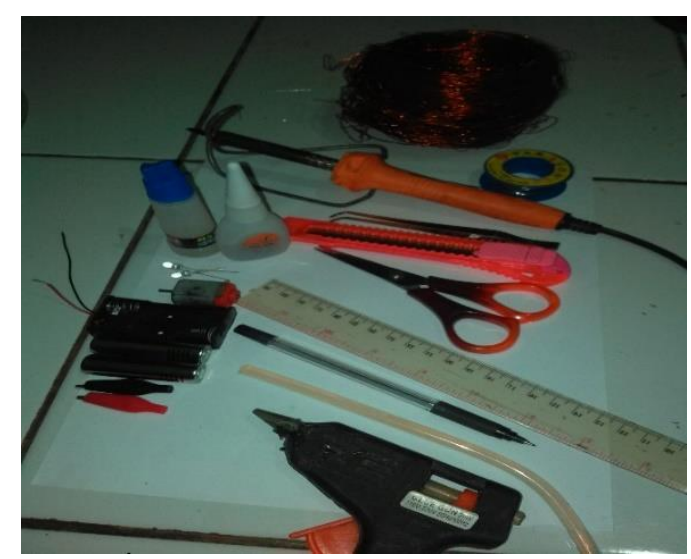

Gambar 1.alat dan bahan untuk membuat BOXTARIK

Cara membuat BOXTARIK:

1. Belah botol oli bekas tersebut menjadi dua bagian, dan kemudian bersihkan dari sisa-sisa oli yang masih menempel pada permukaan botol.

2. Buatlah skema pengunci pada botol yang sudah dibelah, dan rekatkan dengan lem altico.

3. Tempelkan dinamo pada salah satu sisi dalam botol oli tersebut menggunakan lem lilin.

4. Lubangi tutup botol oli menggunakan solder dan tempatkan satu lampu led pada lubang tersebut.

5. Kemudian hubungkan kutub positif lampu led dengan kutub positif dinamo menggunakan solder, kemudian buat terminal output menggunakan kawan email. 
6. Rangkai capit buaya yang ada pada holder baterai

7. Tempelkan holder baterai yang sudah dirangkai pada botol oli yang ada dinamonya menggunakan lem lilin

8. Lubangi botol oli yang satunya menggunakan solder dengan (3 lubang sejajar dibagian atas, dan 3 lubang sejajar dibagian bawah)

9. Rangkai lampu led dengan rangkaian yang berbeda (3 baris rangkaian seri, dan 3 baris rangkaian paralel)

10. Kemudian potong kardus bekas yang ada seukuran $5 \times 7 \mathrm{~cm}$, dan tempelkan konten yang bisa digunakan untuk menjelaskan deskripsi baterai dan proses oksidasi dan reduksi.

11. BOXTARIK sudah jadi.

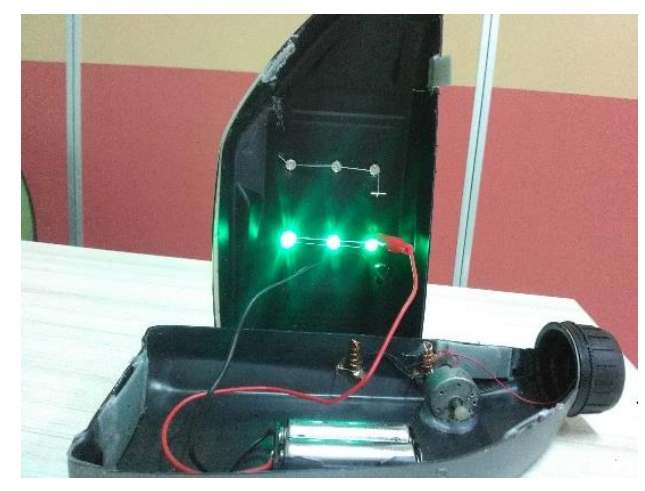

Gambar 2.BOXTARIK

Dalam perancangan BOXTARIK ini, ada beberapa konten materi fisika dan kimia yang dapat disampaikan dalam pembelajaran. Beberapa materi tersebut merupakan materi yang berkenaan dengan kelistrikan. Namun tidak menutup kemungkinan materi yang lain pun juga bisa dimasukkan dalam BOXTARIK ini, yang pasti materi-materi tersebut sudah terkonsep dalam bentuk yang lebih sederhana sehingga bisa lebih mudah difahami oleh siswa. Diantara beberapa materi yang bisa disampaikan dalam BOXTAR ini yaitu:

1. Konversi energi

Energi sebetulnya tidak dapat dihasilkan dan tidak dapat dihilangkan, energi hanya berpindah dari suatu bentuk ke bentuk energi yang lainnya. Pada BOXTARIK ada beberapa hal yang bisa menjelaskan konsep konversi energi ini, yaitu: perubahan energi gerak menjadi listrik, dan perubahan energilistrik menjadi gerak, panas, dan cahaya. Eenergi listrik akan berpindah menjadi energi cahaya jika anergi listrik tersebut melewati suatu lampu, energi cahaya akan berpindah menjadi energi panas ketika bola lampu tersebut pemakaiannya lama, demikian seterusnya.

2. Motor listrik dan generator

Dalam menjelaskan materi terkait dengan motor listrik dan generator bisa dengan menggunakan dinamo 
yang sudah ada dalam BOXTARIK.

Ketika dinamo tersebut dialiri arus listrik dan bergerak (berputar), maka dinamo tersebut berperan sebagai motor listrik. Namun, ketika dinamo tersebut digerakkan dan menghasilkan arus listrik sehingga lampu LED menyala, disitu dinamo berberan sebagai generator. Dalam konteks menjelaskan materi ini, dinamo mempunyai dua peran sebagai motor listrik dan generaor karena tipe dari dinamo yang digunakan tersebut yaitu dinamo DC. Selain penyampaian konsep motor listrik dan generator, kita juga bisa menyampaikan beberapa hubungan dari arus listrik yang dibutuhkan untok menggerakkan motor listrik, dan arus listrik yang dihasilkan generator.

3. Medan maghnet

Ketika mengulas materi berkenaan dengan medan magnet, akan lebih baik ketika penyampaiannya disinkronasi dengan materi generator dan motor listrik yang sangat erat hubungan kontennya. Perihalnya kaidah tangan kiri (fleming) yang menentukan arah putaran dari arus listrik yang menghasilkan medan magnet. Hal ini bisa diperagakan dengan mengamati arah putaran dinamo pada BOXTARIK ketika dialiri arus listrik dengan vaiasi kutub positif dan negatif yang berbeda.

4. Rangkaian listrik

Ketika menyampaikan materi berkenaan dengan rangkaian kelistrikan meliputi (rangkaian seri, rangkaian paralel, dan rangkaian kombinasi bisa dengan langsung memperagakannya dengan rangkaian lampu LED yang sudah dirangkai pada sisi bagian atas BOXTARIK, selain bisa memperagakan satu-satu dari tipe rangkaian listrik, bisa juga memperagakan dengan beberapa variasi kombinasi dengan menghubungkannya dengan kabel yang sudah dirangkai dengan capit buaya.

5. Reaksi oksidasi dan reaksi reduksi Untuk menjelaskan konten materi kimia ini, bagian BOXTARIK yang digunakan yaitu baterainya, jadi penjelasan dari adanya reaksi oksidasi dan reduksi bisa disampaikan ketika baterai digunakan untuk beberapa percobaan. Disamping itu, untuk mempermudah penyampaian materi reaksi oksidasi dan reduksi ini, bisa diperkuat dengan simulasi reaksi yang dituliskan di kertas dan 
ditempelkan pada kardus dalam BOXTARIK.

\section{SIMPULAN DAN SARAN}

BOXTARIK ini dirancang sedemikian rupa untuk mempermudah pemahaman siswa berkenaan dengan materi yang dirasa akan lebih mudah dipahami ketika diperagakan dengan media peraga. Seperti halnya sistem kelistrikan dan hubungannya dengan materi fisika dan kimia seperti konversi energi, motor listrik dan generator, medan magnet, rangkaian listrik serta reaksi oksidasi dan reduksi. Dengan adanya desain pertama BOXTARIK ini diharapkan bisa meningkatkn proses pembelajaran di sekolah menengah. Namun penulis menyadari bahwa dalam penyusunan BOXTARIK ini masih banyak kekurangan, oleh karena itu, saran yang membangun senantiasa diharapkan oleh penulis.

\section{UCAPAN TERIMA KASIH}

Penulis menucapkan banyak terimakasih kepada beberapa pihak yang telah membantu sehingga penulisan ini bisa diselesaikan

\section{DAFTAR PUSTAKA}

Anitah, S. (2010). Media Pembelajaran. Surakarta: Yuma Pressindo.

Atmojo, s. E. (2017). Pengembangan Perengkat Pembelajaran IPA Terpadu Berpendekatan Ethnosains. Pendidikan Sains , 5.

Dilaga, D. S. (2012). Wawasan Teknologi Pendidikan. jakarta: Kencana.

Nuzulia, W. F. (2016). Media Limbah Botol Untuk Meningkatkan Pembelajaran PAI Di RA Miftakhul Khoir 1 Karangrejo. Al-Murabbi, 2. Riyana, R. S. (2008). Media Pembelajaran. Bandung: $\quad \mathrm{CV}$ Wacana Prima.

Sulistyorini, S. (2007). Pembelajaran IPA Sekolah Dasar. Semarang: Tiara Wacana.

sutjipto, K. d. (2011). Media Pembelajaran Manual dan Digital. Bogor: Ghalia Indonesia.

Usman, A. d. (2002). Media Pembelajaran. Jakarta: Ciputat Pers.

Wilujeng, I. (2011). MEMBUMIKAN IPA TERPADU (Apa, Mengapa, danBagaimana IPA Terpadu). Stadium General Program Studi Pendidikan IPA (pp. 3-4). Semarang: Universitas Negeri Semarang. 